\title{
Los nuevos movimientos sociales, el uso de las TIC y su impacto social
}

\section{New Social Movements, the Use of ICTs, and Their Social Impact}

\author{
Fernando Flores Morador [CV] History of Ideas and Sciences Department, Lund University, \\ Suecia. fernando.flores@kultur.lu.se
}

Judith Cortés Vásquez [CV] Departamento de Comunicación y Arte Digital, Instituto Tecnológico de Monterrey, Campus Querétaro, México jcortesv@itesm.mx

\begin{abstract}
[ES] El siguiente trabajo es el resultado una revisión sobre los Nuevos movimientos sociales y el uso de las nuevas tecnologías, vistos a la luz de la filosofía política. Esta reflexión parte de los resultados obtenidos en la tesis doctoral sobre "Nuevos movimientos sociales y uso de las TIC. Estudio de casos" presentada en la Universidad Complutense de Madrid en el doctorado de Comunicación, Cambio Social y Desarrollo. Si bien estos movimientos han existido desde hace mucho tiempo, las nuevas tecnologías digitales permiten la visualización, expansión y divulgación mayor de sus agendas y propuestas. El "saber hacer" de estos nuevos movimientos y su capacidad de transformación social, son expresión de un marco de estrategias diferentes a las propuestas por los grupos tradicionales enmarcados en los partidos políticos. Las metodologías de acción civil requieren de un flujo natural de la información, que los partidos políticos no pueden reproducir. Los recursos simbólicos y las expresiones de sentimientos y emociones, saltan a la palestra del juego social configurando un nuevo lenguaje, una manera distinta de ser. Más allá de la implicaciones mediáticas y políticas, hay un trasfondo en términos de cambio social profundo.

[EN] The following work is an analysis of new social movements and the use of new technologies from the perspective of political philosophy. It stems from the results obtained in the dissertation "New Social Movements and the Use of ICTs: Case Studies," presented at the Universidad Complutense de Madrid as part of the Communication, Social Change and Development program. While it is true that these movements have existed for a long time, new digital technologies allow for political agendas and proposals to increase in visibility, scope and dissemination. The "know-how" of these new movements and their ability to drive social transformation are expressions of a framework made up of different strategies to those proposed by traditional groups framed by political
\end{abstract}




\section{Revista Latina de Comunicación Social \# 071 - Páginas 398 a 412}

\begin{tabular}{l|l|l|l} 
Investigación financiada & DOI: 10.4185/RLCS-2016-1101 & ISSN 1138-5820 & Año 2016
\end{tabular}

parties. The methods employed by civic action require a natural flow of information which political parties cannot reproduce. Symbolic resources and expressions of sentiments and emotions play a crucial role in structuring a new form of language and a different way of being. The implications are important, not only in terms of mass media and politics, but also in terms of social change.

\section{Keywords}

[ES] Nuevos movimientos sociales; tecnologías de comunicación; cambio social; tecnocracia.

[EN] New social movements; communication technologies; social change; technocracy.

\section{Contens}

[ES] 1. Introducción. 2. Metodología 3. El surgimiento de la tecnocracia 4. El trabajo Voluntario. 5. Relación entre tecnócratas y capitalistas 6. La resistencia a las nuevas formas de explotación. 7. La crisis de credibilidad de los partidos político. 8. Las TIC y Nuevos Movimientos Sociales. 9. Conclusiones. 10. Bibliografía.

[EN] 1. Introduction. 2. Methodology. 3. The Rise of Technocracy. 4. Volunteer Work. 5. Relationship Between Technocrats and Capitalists. 6. Resistance to New Forms of Exploitation. 7. New Social Movements. 8. The Credibility Crisis of Political Parties. 9. ICTs and New Social Movements. 10. Conclusions. 11. Bibliography.

\section{Introducción. La crisis de la filosofía política}

El lugar de la teoría social es el de proveer al militante de un marco para la acción política. Durante decenios, esta teoría social fue provista por las ideas de Carlos Marx, referencia teórica natural de los militantes de "izquierdas" de todo el mundo. Curiosamente a partir de 1989 se instaló la convicción creciente de que el modelo marxista se había obsoletizado. Esencialmente, la atracción del marxismo radicaba en la riqueza y profundidad de sus interpretaciones de la historia, ideas que permitían comprender fenómenos que aparentemente estaban desconectados entre sí: política, economía, ideología, etc. Generando así una visión holística de los hechos, dando explicaciones mucho más complejas a los hechos observados, pero si bien esto era evidente, ¿por qué perdió fuerza el marxismo en ese momento? Permítasenos aquí comentar algunas de las razones de la crisis del marxismo. En su metáfora del "edificio social", Marx nos habla de una infraestructura económica que actúa como base social y de una superestructura jurídico-política. Como consecuencia de ello su concepción de la sociedad, no tiene lugar ni para el conocimiento ni para el lenguaje. Esto ya hubo de ser apuntado por Stalin (lenguaje) y por Althusser (ciencia, experiencia y conocimiento).

De esta forma, la carencia es significativa; por ejemplo, Marx define al capitalista como aquél que es dueño de los medios de producción, aquel que emplea mano de obra asalariada. Pero nada dice que para ello el capitalista debe saber "hacer" capitalismo, debe tener el oficio de capitalista. El capitalista, como el carpintero, es un técnico, pertenece a un grupo social que durante siglos desarrolló un conjunto de tecnologías tan viejas como la humanidad. "Capitalistas" en el sentido técnico, hubo desde que existió usura. Aristóteles distinguía ya entonces, entre dos formas fundamentales de la administración de valores, una la "económica", la cual se refería a la administración del hogar, la otra la "crematística", se refería a las formas de ganar dinero. Así el concepto de capitalista se nutrió de estas dos concepciones, sumando en su noción parte de las dos formas administrativas. 


\section{Revista Latina de Comunicación Social \# 071 - Páginas 398 a 412 \begin{tabular}{l|l|l|l} 
Investigación financiada & DOI: 10.4185/RLCS-2016-1101 & ISSN 1138-5820 & Año 2016
\end{tabular}}

Por otro lado, cabe señalar, que todos los oficios del poder, se ejercen sobre la base del "saber hacer", lo que supone el dominio del lenguaje específico del oficio. Por supuesto que estas capacidades técnicas se heredan, se transmiten de padres a hijos a través de las generaciones y tienen por tanto una raíz étnica. A Marx se le escapó que más que en la arena política, la lucha de clases se regula a través de los matrimonios. Es así que dentro de las aristocracias se crían los bastardos, plebeyos con poder; ya como generales, ya como políticos, ya como sacerdotes; del Antiguo Imperio Romano, al feudalismo germánico y de éste al capitalismo inglés. Todos ellos están relacionados por lazos de sangre, pertenecen a la misma gran casta de los que controlan el saber.

Por otro lado, tenemos a los que carecen de todo saber, a quienes solo es posible distinguir como "masa social". Este gran grupo se origina en la división de las sociedades arcaicas en etnias endógenas que esclavizaban al extranjero para hacerles cumplir las tareas menos calificadas. Al esclavo se le dificultaba -sino se le impedía completamente- el cultivo de los propios valores culturales, condenándole a la realización de tareas embrutecedoras. Es así que el esclavo devino siervo y éste en su momento devino obrero para ser hoy el profano en la sociedad del conocimiento; por supuesto, estos a su vez están también relacionados entre sí por lazos de sangre. La historia de la literatura registra como excepciones paradigmáticas el amor entre nobles y plebeyos, pobres y ricos, esos encuentros casi imposibles de amores que superaban las barreras sociales más altas. Así, la lucha del esclavo fue por conquistar un lugar en la cultura, un espacio en la sociedad de los hombres, reduciendo en esta lucha las distancias culturales con el saber de los poderosos.

En resumen, se podría decir que en tanto que saber es poder, la lucha de clases ha consistido sobre todo en una lucha por el saber. En ésta, tanto el esclavo como el amo han cambiado, han asimilado experiencias incorporadas a la base inconsciente de la sociedad, al acervo de sentimientos y emociones que constituyen la modernidad y que son la expresión de la irreversibilidad de la experiencia. Esta modernización, asegura el desarrollo paralelo de lo que podríamos llamar la "sociedad civil", es decir, el conjunto creciente de instituciones y leyes que refuerzan la unidad entre los hombres, debilitando para ello la unidad de las etnias y los grupos en general. Esa sociedad civil está al margen del edificio social de Marx. Pitágoras por ejemplo, fue la consecuencia de una sociedad que ya no existe, a pesar de ello, sus matemáticas siguen vigentes; pertenecen al acervo de la humanidad toda. De forma similar, la sociedad civil es el reservorio del saber humano, el inconsciente colectivo y como tal es una realidad paralela a la lucha de clases.

\section{Metodología}

El trabajo que se presenta es fruto de la reflexión hecha en función de la tesis doctoral denominada "Nuevos movimientos sociales y uso de las TIC. Estudio de casos" elaborado por la Dra. Judith Cortés Vásquez en donde se estudió la marcha organizada desde el grupo de Facebook "Un millón de voces contra las FARC" en Colombia y el caso italiano de "Amici di Beppe Grillo di Napoli" presente en la plataforma Meetup. Estos dos casos fueron estudiados desde sus antecedentes históricos y se realizó una encuesta online que buscaba analizar las motivaciones que los llevaron a pertenecer a los grupos estudiados, las formas de participación online y offline, el perfil de los miembros, la percepción del impacto social de las acciones, el valor simbólico y real de las mismas, entre otros factores.

Para la realización de este estudio, se manejaron fuentes primarias y secundarias sobre cada uno de los movimientos. Para conocer las particularidades de los movimientos se trabajó con encuestas online que se aplicaron a los miembros de cada grupo utilizando la lógicas propias de cada plataforma. Ha sido importante realizar esta encuesta usando internet debido a la distribución de 


\section{Revista Latina de Comunicación Social \# 071 - Páginas 398 a 412 \begin{tabular}{l|l|l|l|} 
Investigación financiada & DOI: 10.4185/RLCS-2016-1101 | ISSN 1138-5820 & Año 2016
\end{tabular}}

quienes participaron en el grupo, siendo una forma de acercarse al mundo virtual en el que se dieron las acciones. Igualmente se trabajó con información obtenida directamente del comité organizador del evento con quienes se mantuvo contacto para obtener información específica del grupo mediante entrevistas.

En el caso del grupo colombiano, como fuentes secundarias, al ser este un acontecimiento mediático con un alto grado de presencia a nivel nacional e internacional, se seleccionaron como fuentes secundarias los siguientes medios: Periódico El Tiempo, el periódico más importante de Colombia y la Revista Semana, la de mayor impacto nacional. Igualmente se retomaron documentos con estudios y publicaciones hechas en diferentes medios de comunicación en línea. Archivos online de la emisora de radio de Caracol, que constituye la primera cadena radial de Colombia y que cuenta con una base de datos actualizada que permite el estudio de distintos documentos.

\section{Población y muestra}

Se trabajó con el universo de usuarios de la plataforma de Facebook tomando como población a los usuarios miembros del grupo "Un millón de voces contra las FARC" nacido el 4 de enero del 2008, que para el 26 de abril del 2008 era de 358.190 miembros y que a 11 de mayo del año 2009 contaba con 445.448 miembros. Del total de miembros del grupo de Facebook "Un millón de voces contra las FARC" al 11 de mayo del 2009 que era de 445.448, se obtuvo una participación de miembros activos de los cuales 441 personas decidieron contestar la encuesta online conformando así la muestra de esta investigación.

Para el grupo Amici di Beppe Grillo di Napoli, el cual contaba al 20 de febrero del 2011 con 4419 miembros en la ciudad de Nápoles, se obtuvo una participación de 210 personas que participaron en la encuesta. El total de miembros del grupo de Meetup de Beppe Grillo era para esa fecha de 77.422 miembros distribuidos en 283 ciudades en 11 países alrededor del mundo.

Con esta muestra de activistas que respondieron las encuestas online, se obtuvo información sobre la forma de actuar de estos movimientos sociales utilizando las plataformas online para hacer presencia offline. La reflexión que se presenta a continuación se ha realizado partiendo de los resultados obtenidos en esta investigación.

\section{El surgimiento de la tecnocracia}

Dentro del marco descrito anteriormente, la lucha por el saber, o sea por ocupar un lugar en la cultura, no es otra cosa que lo que Marx llamó "lucha de clases". Su propuesta fue la de la revolución, la expropiación por la fuerza del saber social en manos de los poderosos. Lo que Marx no consideró, fue descubierto tardíamente por Lenin, a saber que no es posible romper con las castas de sabios mediante el recurso de medidas puramente políticas. No alcanza con "crear consciencia", es necesario sobre todo "crear inconsciencia", es decir, modificar a largo plazo las herencias arcaicas del saber social reforzando la sociedad civil. Pero este error ha demorado hasta hacerse obvio. Sobre sus bases precarias, el marxismo triunfó en innumerables batallas políticas hasta que en 1989 sucedió lo inevitable: implosionó; se desplomó como un castillo de naipes. Desde un principio, la revolución rusa había relegado a la sociedad civil; el poder fue usurpado por los nuevos sabios: "el partido de las vanguardias". Así, la tecnocracia del partido, en su mayoría individuos provenientes de las clases medias educadas, se pusieron a hacer lo que siempre supieron hacer, ejercer el poder. Esta vez el discurso fue otro, aunque el resultado fue el mismo. La historia es conocida, la dictadura del proletariado exigió enormes sacrificios a las grandes mayorías y la recompensa a cada triunfo fue la 


\section{Revista Latina de Comunicación Social \# 071 - Páginas 398 a 412 \begin{tabular}{l|l|l|l|} 
Investigación financiada & DOI: 10.4185/RLCS-2016-1101 & ISSN 1138-5820 & Año 2016
\end{tabular}}

exigencia de un mayor sacrificio. Se hizo obvio que los estados comunistas perdían muy rápidamente el apoyo de su población. Las carencias evidenciadas en la historia de la URSS autorizarían la teoría argumentada por muchos marxistas de que en la URSS el poder había caído en manos de una nueva clase dominante, la de los tecnócratas o burócratas.

El sorprendente colapso de la URSS nos autoriza a un examen más cercano de esta hipótesis. ¿Nueva clase dominante? Para empezar deberíamos ver síntomas del surgimiento de un nuevo modo de producción. Este podría ser el enmarcado en la revolución "científico-técnica", estudiada en detalle por John D. Bernal (1901-1971) y Radovan Richta (1924-1983). Este último, en su obra La Civilización en la Encrucijada (1972) vio en la incorporación de la automación a los procesos productivos la sustitución de los trabajadores industriales por una nueva clase de expertos económicos, ingenieros y científicos. Para Richta y los ideólogos de la abortada revolución Checa, la sociedad entraba en una nueva época que ellos asociaban al socialismo. Lamentablemente, sus teorías fueron aplastadas por los tanques rusos en 1968 y lo que prometía ser un desarrollo interesante quedó en la nada. Creemos que Richta y sus colegas comprendieron que un nuevo modo de producción había nacido, uno que se definiría por la entronización de los procesos automáticos en la sociedad, procesos que se han acelerado gracias a la digitalización de la misma.

El nuevo modo de producción habría nacido con la revolución técnica generada de la mano de la inteligencia artificial, de la cibernética y del desarrollo de los ordenadores. Todo esto sucedió a partir de la Segunda Guerra Mundial, provocando más tarde la digitalización de la vida social en su totalidad. Llamemos a este, Modo Tecnócrata de Producción Automatizada. De acuerdo a las reflexiones de Richta, el nuevo modo de producción tenía su base fundamental en los EEUU y en los países capitalistas de Europa occidental, además de mostrarse con fuerza en la URSS. Estaríamos entonces frente a un nuevo modo de explotación, la del poder "tecnocrático". De ser así, y siempre dentro del marco formal del materialismo histórico, necesitaríamos además descubrir una clase explotadora, una clase de explotados y un marco para la explotación. Deberíamos de ser capaces de descubrir los nuevos caminos de la generación de la plusvalía. Todo esto nos acerca a hablar de una forma distinta de trabajo: el trabajo voluntario.

\section{El trabajo voluntario}

En la revolución socialista de la URSS, la estructura económica estuvo basada en el trueque de servicios, es decir, el intercambio de valores se basó en la relativa utilidad inmediata de un ítem. El consumidor de la URSS recibía una lista de ítems disponibles y ajustaba su consumo de acuerdo a esa disponibilidad. Así, el consumidor de la antigua Unión Soviética iniciaba así un proceso de destronización de consumidor en beneficio del plan tecnocrático. A este mecanismo se llamó "economía planificada". El consumidor socialista se adaptaba a lo que había, justificando las decisiones que la tecnocracia había tomado. Visto en perspectiva, observamos que este proceso trascendió las fronteras del mundo socialista desarrollándose con más efectividad en el mundo capitalista. En la esfera capitalista, la destronización del consumidor viene acompañada de la explotación del mismo como "trabajador". En la sociedad capitalista contemporánea, la explotación del trabajo asume formas muy sutiles. Se organiza de modo que una parte creciente del trabajo se carga al consumidor.

De esta manera, una parte creciente de la tarea en la sociedad automatizada asume la forma de trabajo voluntario del consumidor, se asienta en la consigna "hazlo por ti mismo". En la sociedad contemporánea, un número creciente de empresas obliga al consumidor a realizar una parte creciente de la labor. El argumento manejado es revelador; los cambios se hacen para beneficiar al 


\section{Revista Latina de Comunicación Social \# 071 - Páginas 398 a 412 \begin{tabular}{l|l|l|l|} 
Investigación financiada & DOI: 10.4185/RLCS-2016-1101 | ISSN 1138-5820 & Año 2016
\end{tabular}}

consumidor, "abaratando los costos se abaratan también los precios". Que los costos se reducen no cabe duda, en tanto el capitalista no debe asumir los costos de una parte importante de la mano de obra. ¿Pero no aumentan también las ganancias de la empresa? Observamos que para llevar a cabo la transferencia del eje del trabajo desde el productor al consumidor, la empresa capitalista debe automatizar una buena parte de su administración y producción.

En otras palabras, debe someterse a una reestructuración tecnocrática. Indirectamente, la plusvalía generada por el trabajo gratis del consumidor, financia el desarrollo de la clase de los tecnócratas. Pero esta nueva casta del poder, colabora con el capitalista; observamos, una vez más, la colaboración de las clases dominantes en un momento de transición social. Decimos que la empresa contemporánea es capitalista en la medida en que basa su acción en la apropiación de la plusvalía directa del trabajo de un asalariado. Por otra parte, decimos que una empresa es tecnocrática si se apropia de la plusvalía a través del trabajo directo del consumidor. Luego, empresas "mixtas" serán aquellas que combinen el trabajo remunerado con el trabajo voluntario. Un ejemplo de empresa tecnocrática sería Microsoft; un ejemplo de empresa mixta sería la tienda de muebles sueca IKEA. A diferencia de lo sucedido en la URSS, en los países capitalistas el consumidor se provee de los ítems que necesita en el mercado abierto y no a través de una lista. La existencia de este mercado, disimula el poder y presencia de la tecnocracia. De esta forma el "consumismo" se justifica como una nueva forma de la explotación del trabajador.

\section{Relación entre tecnócratas y capitalistas}

Es importante comprender cómo se da la relación entre tecnócratas y capitalistas, para poder comprender la forma de interacción de los dos. A cada paso en el proceso de automatización de la sociedad, más poder se transfiere a la esfera tecnocrática. La tecnocracia trabaja desde dentro del capitalismo, le coloniza, erosionando su poder desde dentro. Como en ejemplos anteriores de transición social, la tecnocracia se genera a la sombra de la clase dominante, es decir a la sombra de los capitalistas. Del mismo modo que los tecnócratas arraigados en el partido comunista de la URSS se apropiaron del poder de éste, el colonialismo tecnócrata en los países capitalistas sustituye al poder capitalista; pero en este caso lo hace gradualmente, aumentando su poder poco a poco desde dentro de la empresa capitalista.

Es esencial tener claro que la tecnocracia no trabaja gratis; pero vive del trabajo gratis del resto de la sociedad, es decir del trabajo de los profanos (consumidores). Para Marx, la relación de explotación fue físicamente directa y unívoca: el esclavo trabaja para el amo; el obrero para el capitalista; el sometido trabaja para el que le somete. Pero el tecnócrata, trabaja para aquel a quien somete. El trabajo del tecnócrata desmonta el poder del capitalista, (del amo) en tanto le reduce gradualmente a profano, erigiéndose en su lugar como el nuevo amo. El capitalista explota al experto y el experto explota al capitalista hasta que a la larga, el experto triunfa. Porque el poder social nunca radicó ni en las armas, ni en el dinero, ni en ninguna otra forma materializada del poder sino en saber usar las armas y saber usar el dinero. Mientras que en la sociedad capitalista el valor se mide en saber usar el dinero, en la sociedad tecnócrata el valor se mide en saber usar la información en general.

Así, en tanto en el modo tecnócrata de producción, el dinero se ha convertido en información, el saber del capitalista se ha obsoletizado. Tal y como sucedió en transiciones anteriores, el nuevo modelo social se basa en el preexistente para desmontarle poco a poco. A diferencia del capitalismo que buscaba apropiarse de la plusvalía del trabajador, la explotación tecnócrata busca hacerse con la plusvalía de toda la sociedad y no solamente la de los trabajadores directamente comprometidos. De allí que su estatus social no pueda reducirse al estatus del capitalista. 


\section{Revista Latina de Comunicación Social \# 071 - Páginas 398 a 412}

\begin{tabular}{l|l|l|l} 
Investigación financiada & DOI: 10.4185/RLCS-2016-1101 | ISSN 1138-5820 & Año 2016
\end{tabular}

Por otro lado, en tanto clase colonizadora, el experto puede adaptarse a todos los grupos y puede vivir de la plusvalía generada por todos ellos en tanto consumidores. Para el marxista, la razón económica nace en torno a los procesos de explotación de la fuerza de trabajo, mientras que el resto de la sociedad va detrás, asumiendo un rol secundario y pasivo. La explotación de la fuerza de trabajo en el modo de producción tecnócrata por el contrario, tiene lugar en todos los niveles y grupos sociales simultáneamente. En tanto que consumidores, la explotación tiene lugar en la familia, el club deportivo, el sindicato, el partido político, en la iglesia, el hospital, etc. En resumidas cuentas, todos los consumidores trabajan para el tecnócrata.

\section{La resistencia a las nuevas formas de explotación}

Ante el avance de la tecnocracia, los profanos se organizan para fortalecer la sociedad civil. Obsérvese que la respuesta profana asume la forma de oenegés. Apoyadas éstas en el crecimiento masivo de nuevas ideologías "posmodernas" tales como el feminismo, el ecologismo, el animalismo, el pacifismo, el humanismo, etc. Las oenegés, capitalizan la desconfianza generalizada en los partidos políticos, en la administración del estado, en el mundo de las finanzas y en general en los miembros del establishment a quienes se identifica con la clase de los tecnócratas. De la misma manera que los líderes obreros provinieron en su momento de las clases medias burguesas, los líderes profanos surgen entre los tecnócratas más conscientes. Ejemplo de figuras prominentes de la resistencia profana podrían ser Julián Assange y Edward Snowden, comprometidos con la tarea de desmontar la sociedad tecnócrata por lo que han sufrido cárcel y persecución. El profano militante, nuevo héroe de la historia, organizado con el fin de fortalecer la sociedad civil, habrá de trabajar para desfetichizar la tecnología; habrá de denunciar los alcances inadmisibles de la automatización en tanto deshumanización. Ante el riesgo de la colonización tecnócrata, el profano trabajará para desmontar el poder del grupo de los sabios, porque es en la lógica de los grupos sabios en donde la tecnocracia ejerce su poder. En su lucha contra la tecnocracia, el profano se uniría al obrero en su lucha contra el capitalismo, advirtiendo a este de los riesgos de la colonización tecnócrata de las organizaciones obreras y de los riesgos derivados de las alianzas entre capitalistas y tecnócratas.

\section{Los nuevos movimientos sociales}

Si bien los cambios parecieran ser más evidentes en las esferas económicas de la sociedad, resulta igualmente destacados los cambios dados a nivel de orden social con incidencia política. Así, el grupo de "Un millón de voces contra las FARC" y "Amici di Beppe Grillo di Napoli" se apropian de labores especiales del estado, los cuales al no ser ejecutados por las instancias de gobierno, terminan siendo asumidas como responsabilidad por la sociedad civil. Esta apropiación incluye desde las temáticas que involucran a grupos específicos, hasta la movilización por la naturaleza y protección del cambio climático.

En el caso del grupo "Un millón de voces contra las FARC" como lo muestran los resultados obtenidos en la investigación en relación con las motivaciones para unirse al grupo:

Dentro de los múltiples motivos, se destacan tres: "Me vinculé por compromiso con la paz" (89.55\%) llega a un casi $90 \%$, seguida de "Me vinculé por compromiso con Colombia" con un $(88,7 \%)$ y "Me vinculé porque es una forma para expresar mi descontento con la situación". $(86,61 \%)$. Al final son la paz, el compromiso por Colombia y el descontento con la situación, los tres principales ejes que movieron la participación en el grupo. Resulta relevante ver cómo el factor político queda rezagado entre los motivos para participar. (Cortés, 2011: 357) 


\section{Revista Latina de Comunicación Social \# 071 - Páginas 398 a 412 \begin{tabular}{l|l|l|l|} 
Investigación financiada & DOI: 10.4185/RLCS-2016-1101 | ISSN 1138-5820 & Año 2016
\end{tabular}}

Al final, es la búsqueda de la paz, el compromiso con el país el descontento ante la realidad nacional las que llevan a los ciudadanos a participar. Su decisión no solo responde a consideraciones racionales, sino que expresan abiertamente factores de tipo emocional "Considerando que existían motivos emocionales que acompañaban la decisión de sumarse al grupo, se destaca el sentir de "Deseo la paz para Colombia" 95.75\% y la "solidaridad con los secuestrados y sus familiares" 89.69\%." (Cortés, 2011: 357) De fondo la paz y la solidaridad determinaron la participación de los miembros.

Como lo señala Jesús Ibarra, los movimientos sociales se caracterizan por una notable capacidad de informalidad organizativa, por el desarrollo y aplicación de métodos no convencionales, actualizando redes preexistentes disponibles para canalizar las ideas emergentes. Agrega, Ibarra, que son grupos poseedores de prácticas flexibles; con acciones espectaculares demuestran más audacia mediática que las acciones rutinarias propias de los partidos o grupos de interés tradicionales; aprovechan y dominan las TIC las cuales les permiten facilitar los procesos de comunicación y decisión, acortando las distancias y tiempos. Los nuevos movimientos sociales (NMS) cumplen con algunas cualidades generales establecidas por Hank Johnston, Enrique Laraña y Joseph Gusfield (2001) en el libro "Los nuevos movimientos sociales. De la ideología a la identidad." Estos autores identifican ocho parámetros que engloban parte de las condiciones propias de estos nuevos movimientos:

1. Los seguidores de los grupos NMS no están organizados de una manera definida. Establecer los perfiles de quienes participan en estos grupos se convierte en una difícil tarea debido al origen social difuso de sus miembros. La edad, el género y la formación profesional de sus miembros es heterogénea; el rasgo común es la diversidad y la diferencia.

Cabe señalar que en cuanto a los grupos estudiados, los resultados en términos de perfil de usuario resultaron muy similares. En el caso del grupo Amici di Beppe Grillo di Napoli: "De los miembros que participaron en la encuesta, el $69.8 \%$ corresponde a hombres y el $30.20 \%$ a las mujeres. Presentando un porcentaje muy similar al caso de Colombia en Facebook" (Cortés, 2011: 363) Igualmente en cuanto a nivel de formación académica en el grupo de Facebook, "El grupo de ciudadanos encuestados, contaron con un nivel de instrucción en donde el $50 \%$ eran universitarios; el $40 \%$ habían cursado escuela media superior; un $8 \%$ escuela media y un $2 \%$ contaban con estudios de máster o doctorado." (Cortés, 2011: 295) Cifras muy parecidas a las presentadas en el grupo italiano. Queda claro que son las personas con mayor nivel académico las que lideran, crean y promueven este tipo de activismo.

2. Sus características ideológicas contrastan notablemente con las del movimiento obrero y con la concepción marxista de la ideología como el elemento unificador y totalizante de la acción colectiva. Estos movimientos no se pueden clasificar en términos de izquierda/derecha, liberal/conservador, socialistas/capitalistas. El mismo perfil diverso de sus miembros y el poco interés por establecerse como parte de una línea ideológica especial, genera un pluralismo tanto en ideas como en valores, lo cual caracteriza su condición ideológica y su verdadero interés se centra en cuestiones pragmáticas las cuales buscan transformaciones institucionales permitiendo la participación en decisiones de interés colectivo. Esta visión es muy evidente en el caso del grupo "Amici di Beppe Grillo di Napoli" como lo señalan en la tesis.

En este punto, se destaca el reconocimiento como movimiento político por parte de los miembros del grupo, este es un caso particular en donde se habla de "apolítica" y distanciamiento de esta estructura de poder. Buena parte del discurso que se maneja al interior del grupo es muy crítico frente a las instituciones formales de gobierno y genera buena parte de su información en contra 


\section{Revista Latina de Comunicación Social \# 071 - Páginas 398 a 412 \begin{tabular}{l|l|l|l|} 
Investigación financiada & DOI: 10.4185/RLCS-2016-1101 & ISSN 1138-5820 & Año 2016
\end{tabular}}

de estas estructuras del país. El reconocimiento amplio del grupo como una institución política resulta de gran importancia pues debe reconsiderarse este punto dentro del discurso del grupo pues en algunos casos puede llegar a generar problemas de identidad entre los miembros del grupo que se reconocen o no como parte de las estructuras políticas del país. (Cortés, 2011, p. 288)

Así, más que sumarse a una línea ideológica específica, lo que persiguen es abrirse un camino desde la dinámica de la igualdad de oportunidades participativas. Los integrantes de los NMS se comprometen con la intensión de solucionar problemas específicos. Definen con precisión los problemas que se abordan y sus acciones tienden a ser prácticas y precisas. En muchos casos, hacen una crítica hacia la ideología del "progresismo", luchan contra el consumismo y el utilitarismo y ubican lo "social" por encima de lo económico.

De ahí la distancia respecto a los intereses de los movimientos obreros. La ideología de las NMS muestran dos rasgos básicos: 1) la preocupación por las amenazas a la vida, léase: contaminación, enfermedades, discriminación, escasez de recursos naturales, extinción de especies, entre otras. 2) Por otro lado, "la lucha por un mundo mejor", por la paz en la convivencia, respetando los derechos humanos básicos, por los derechos de la mujer y los niños, por una integración cultural. Los nuevos movimientos implican el desarrollo de nuevos aspectos de la identidad de sus miembros. Es importante señalar el significativo rol del individuo en el seno de estos movimientos. Muchos de los logros de los NMS se deben a acciones individuales. La acción individual es respetada y valorada, y existe un gran interés por la realización personal de sus integrantes.

Los NMS se erigen en torno a motivadores sociales cercanos a la vida cotidiana, aspectos tales como el de la sexualidad, la alimentación, el cuidado del medio ambiente, el consumo de tabaco en lugares públicos, las formas de diversión y manejo del tiempo libre, entre otros muchos temas se convierten en aglutinantes que motivan a la acción social. Cuestiones de la vida diaria son considerados temas pertenecientes en la esfera familiar fue transforman en temas de interés colectivo.

El manejo de tácticas no-violentas de desobediencia civil caracteriza sus movilizaciones. Estas nuevas formas de la acción social se caracterizan por la creatividad, el romper esquemas utilizando nuevas simbologías. Igualmente, los usos y formas de interactuar en los medios online establecidos, presentan interesantes diferencias en término de géneros. Para el caso colombiano por ejemplo:

Las mujeres expresan sentirse más interesadas en el muro y en los foros de discusión. Ellas establecerían una mayor preferencia a los espacios expresivos siendo menos participativas en procesos de confrontación de posturas. Comparando las preferencias por género, se puede establecer una tendencia de los hombres hacia procesos más participativos (foros) y en el caso de las mujeres hacia procesos más informativos/expresivos (muro). Los foros de discusión resultan mucho más atractivos para los hombres que para las mujeres en un $64.3 \%$ frente a un $34.3 \%$. (Cortés, 2011: 361)

De hecho, buena parte del impacto de los NMS se debe a la fuerza de su capacidad generadora de símbolos; a la innovación en la creación de sentido, y no tanto en la cantidad o magnitud de la movilización.

\section{La crisis de credibilidad de los partidos político}

El florecimiento de los NMS se da paralelamente a la crisis de credibilidad de los partidos políticos, 


\section{Revista Latina de Comunicación Social \# 071 - Páginas 398 a 412}

\begin{tabular}{l|l|l|l} 
Investigación financiada & DOI: 10.4185/RLCS-2016-1101 | ISSN 1138-5820 & Año 2016
\end{tabular}

fenómeno generalizado en la vida pública de las democracias occidentales. El agotamiento de los partidos políticos se debe principalmente a la dificultad creciente de asociar sus actividades al desarrollo de la sociedad civil. Los partidos políticos se agotan en sí mismos, transformando sus actividades en la mera administración de su existencia. A los ojos del ciudadano, la democracia se ha transformado en un tiovivo en el que las mismas soluciones se repiten alternativamente en el tiempo. Los dirigentes políticos a su vez, son identificados como una casta dedicada a la preservación de sus posiciones sociales.

Como contraste la rígida estructura de cuadros y las burocracias centralizadas de los partidos de masas tradicionales, la organización de los NMS tiende a ser difusa y descentralizada. Una de las principales diferencias con respecto a los movimientos sociales tradicionales burgueses y proletarios, se encuentra en las formas organizativas de los NMS; estas son flexibles, con pocos niveles, con roles escasos, con responsabilidades variables y siempre de carácter "profano" es decir no profesionalizados. La tolerancia pluralista de los NMS conduce a un tipo de democracia más directa y participativa. Procuran el desarrollo de una interpersonalidad solidaria oponiendo ésta a la burocracia de los partidos políticos y de los órganos de gobierno. Impulsan estructuras organizacionales descentralizadas y participativas las cuales se refuerzan en la utilización generalizada de las TIC. Para algunos críticos, la suma de estas características debilitará el desarrollo de los NMS con el tiempo; se afirma que al carecer de un programa de acción pensado para una aplicación a medio y largo plazo, se consumirá como un fenómeno de expresión de descontento. Se cree que con el tiempo, los actores de los NMS se dispersarán, los NMS se fragmentarán y atomizarán rápidamente perdiendo su relevancia para sectores importantes de la sociedad. En casos especiales, señalan algunos críticos, que los NMS se transforman en círculos de apoyo emocional y grupos de terapia sin mayores alcances. Es necesario recordar que el ser mutable y poder construirse en un momento determinado y desaparecer para apoyar otros ideales es propio de estos grupos. Así, estas ocho características permiten configurar el sentido, estructura y condiciones propias de los NMS.

\section{Las TIC y Nuevos Movimientos Sociales}

Los movimientos sociales también pueden caracterizarse teniendo en cuenta su relación con las TIC, de esta manera, el trabajo realizado por el profesor Jorge Alberto Machado de la Universidad de Campinas, (Brasil) y presentado en el II Congreso On-line del Observatorio para la Cibersociedad, permite conocer algunas de las cualidades presentes cuando éstos actúan utilizando las redes telemáticas. El autor plantea que gracias a la utilización de las TIC estos movimientos coinciden en:

Proliferación y ramificación de los colectivos sociales. La utilización de las TIC como instrumentos de organización y comunicación ha permitido la proliferación y multiplicación de diferentes organizaciones civiles y colectivos que se ayudan mutuamente trabajando en programas de voluntariado, encontrando en la relación costo-beneficio aspectos muy positivos para generar alianzas y programas de cooperación con otros colectivos. De esta forma la capacidad que tienen las TIC para expandir la presencia de NMS y las posibilidades ofrecidas en términos de expansión en el espacio y en el tiempo son claves en este crecimiento.

Horizontalidad, flexibilidad de las redes. "Las organizaciones tienden a ser cada vez más horizontales, menos jerarquizadas, más flexibles, con múltiples nodos y conectadas a numerosas micro-redes o células" Melucci (1996: 127) las llama redes sumergidas que se pueden activar con rapidez y efectividad. Estas formas de organización establecen un modelo que permite adaptar, ampliar y multiplicar las redes, teniendo una estructura capaz de potencializarse de manera muy 


\section{Revista Latina de Comunicación Social \# 071 - Páginas 398 a 412 \begin{tabular}{l|l|l|l} 
Investigación financiada & DOI: 10.4185/RLCS-2016-1101 & ISSN 1138-5820 & Año 2016
\end{tabular}}

interesante siguiendo unas relaciones descentralizadas y en red.

Las redes pueden activarse y desactivarse, sumarse hoy a una causa y mañana apoyar otras. La continua transformación de las redes y la formación de alianzas estratégicas dan una fuerza significativa a estos NMS.

Tendencia coalizacional. Los autores Butterfoss, Goodman y Wandersman hablan de la coalición desde dos definiciones esenciales, la primera como "una organización de individuos que representan diversas organizaciones, facciones o sectores, que están de acuerdo en trabajar juntos para lograr una meta común" o como una organización compuesta por grupos de distintos intereses, las cuales combinan sus recursos humanos y materiales para lograr un cambio en los miembros quienes son incapaces de lograrlo de forma independiente.

Las coaliciones posibilitan unir a los individuos y grupos con objetivos comunes. De esta forma, sus acciones tienden a ser mediante redes coalizacionales de alcance mundial, en torno a intereses comunes, y con base en la infraestructura de comunicación propiciada por Internet. Esta tendencia todavía ofrece muchos interrogantes sobre la manera en la que se generan esas coaliciones lo que sigue siendo un punto de interés para los estudiosos del tema.

Existencia dinámica o según los hechos. Esta característica de dinamismo hace que los grupos se puedan expandir o desaparecer y transforman el estudio de estos fenómenos en una tarea difícil, debido a que en muchos casos los propios organizadores no saben los alcances posibles de sus convocatorias.

En buena parte de los estudios conocidos como casos paradigmáticos por su gran impacto, quienes iniciaron estos movimientos nunca sospecharon el tipo de alcance que llegarían a tener. "Poseen enorme dinamismo, pueden formarse, alcanzar ciertos objetivos, causar repercusión e impacto, y expandirse por causa de un hecho político; de la misma forma, pueden deshacerse o desaparecer rápidamente, conforme la situación.”(Machado, 2007). Por otro lado, diferentes actividades de las cuales se esperaban fueran a culminar en una gran movilización no lograron los resultados esperados. No existe un camino certero para alcanzar los resultados planeados, por eso muchos de los casos estudiados son fruto de la sumatoria de factores externos que sorprenden por el impacto logrado en los resultados finales los cuales no siempre fueron considerados en la planeación inicial del evento. Igualmente, la comunicación como espacio autónomo que garantiza la organización de la sociedad, se aprovecha de las nuevas tecnologías las cuales son utilizadas como instrumentos vinculantes y de coordinación de acciones, para enfrentar los retos planteados por la sociedad civil. El manejo utilitario y de organización de los medios de comunicación, abre la puerta a múltiples manifestaciones de carácter simbólico y comunicativo, que generan en la ciudadanía una forma diferente de asumir responsabilidades. Como se presentan a continuación, los medios cumplen funciones nuevas entre las que destacan:

Función auto reguladora: Con el libre acceso a los medios de comunicación vía internet, los miembros de la sociedad encuentran espacios abiertos para su acción que resultan ser gestionados y auto regulados por los propios usuarios. Si bien todavía no existe una reglamentación general sobre el uso de los nuevos medios, si existen unas condiciones de control y auto regulación establecidos de forma natural por quienes tienen acceso a la red. El respeto a la norma implícita de estos usos, posibilita una acción coordinada, respetuosa y oportuna por parte de los individuos que se suman a estas nuevas formas de acción social. 


\section{Revista Latina de Comunicación Social \# 071 - Páginas 398 a 412 \begin{tabular}{l|l|l|l} 
Investigación financiada & DOI: 10.4185/RLCS-2016-1101 & ISSN 1138-5820 & Año 2016
\end{tabular}}

Función fáctica. Gracias a la capacidad de acción y ejecución que se genera con los nuevos medios de comunicación e interacción humana, los medios desarrollan de forma efectiva, lo que hemos llamado, función fáctica, entendida como la capacidad de generar acciones y resultados tangibles mediante el uso de las nuevas tecnologías. Los medios vistos desde esta perspectiva, tienen la capacidad de transformar mediante acciones puntuales y concertadas, la realidad. Ya sea para la ejecución de acciones particulares, ofrecimiento de nuevos productos y servicios, los medios de comunicación se convierten en instrumentos de y para la acción.

Función expresiva. Los nuevos movimientos sociales, tienen como eje principal de acción, el establecimiento de nuevas formas expresivas de la realidad, produciendo maneras especiales de comunicar los hechos y generar a la vez emociones que posibiliten la acción y el cambio social. Esta función, resulta de gran relevancia bajo situaciones de amenazante presión social, en donde exponer los diversos puntos de vista, posibilita que la sociedad se exprese y encuentre un espacio de escape, de desahogo que contribuye al mantenimiento estable de la comunidad. En cuanto al ejercicio de poder, los políticos aprenden a escuchar a la sociedad y capitalizan sus inquietudes para hacer eco de una realidad expresada y vivida por la gente. Los políticos, dueños de verdades y soluciones, hoy se transforman en excelentes escuchas que canalizan los intereses e inquietudes de sus votantes. Para ellos, ya no necesita pensar o encontrar la solución, sino que requieren de una escucha atenta.

Los medios de comunicación son el gran escenario expresivo de la sociedad, el derroche creativo que se observa constituye uno de los grandes capitales simbólicos explotados por los usuarios. La resignificación, la riqueza simbólica y la diversidad expresiva serán propios de estos nuevos movimientos sociales. Se llega así con múltiples mensajes, para múltiples audiencias, usuarios o públicos. Cada grupo, logra encontrar su "voz" en el marco de los diversos formatos expresivos.

Función unificadora: Por otro lado, los medios presentarían algunas capacidades propias que le permiten a la sociedad civil alcanzar el logro de sus objetivos, así como la capacidad de generar diálogo, entre diversos grupos, sin importarles tiempo o espacio de los mismos, la capacidad de unir a la gente, siendo agentes vinculadores en donde los límites personales e ideológicos se superan, la capacidad de movilizar a otros y crear movilizaciones sociales, que llevan a la gente a salir del espacio online para expresarse en el offline. La capacidad de auto regular las acciones propias de cada grupo, en donde serán los propios miembros quienes asumen de forma autónoma y natural una forma de auto organización y regulación, hacen posible que estos movimientos impacten realmente en el devenir social así como la capacidad de innovación y creatividad principalmente en los modelos expresivos, con formas originales, que llamen la atención de otros miembros de la sociedad civil.

\section{Conclusiones}

Los nuevos movimientos sociales, vistos a la luz de la filosofía política, proveen a los ciudadanos de un marco alternativo a la acción política. Si bien estos movimientos han existido desde hace mucho tiempo, las nuevas tecnologías digitales permiten la visualización, expansión y divulgación mayor de sus agendas y propuestas. El "saber hacer" de estos nuevos movimientos y su capacidad de transformación social, es expresión de un marco de estrategias diferentes a las propuestas por los grupos tradicionales enmarcados en los partidos políticos. Así, muchos partidos políticos intentan hacer una copia de estas estrategias sin mayores resultados. Las metodologías de acción civil requieren de un flujo natural de la información, que los partidos políticos no pueden reproducir. Los recursos simbólicos y las expresiones de sentimientos y emociones, saltan a la palestra del juego social configurando un nuevo lenguaje, una manera distinta de ser. La sociedad civil organizada, 


\section{Revista Latina de Comunicación Social \# 071 - Páginas 398 a 412 \begin{tabular}{l|l|l|l|} 
Investigación financiada & DOI: 10.4185/RLCS-2016-1101 & ISSN 1138-5820 & Año 2016
\end{tabular}}

hace uso de estos nuevos métodos expresivos llegando incluso a sectores tradicionalmente marginados. La lógica de "hazlo por ti mismo" lleva a los nuevos movimientos sociales a buscar alternativas que solucionen sus problemas locales-globales.

Frente a la desesperanza producida por los partidos políticos, la sociedad civil se empodera a través de las oenegés desarrollando nuevas formas de cambio social. Comprometerse como "profano" en la sociedad del conocimiento es, en pocas palabras, trabajar por el desarrollo de una nueva sociedad en la que la perspectiva social dominará sobre los intereses de grupos (inclusive las clases). Lo hará a través de fortalecer los derechos humanos en general, los derechos a la salud y a la educación de propios y sobre todo de ajenos. La militancia profana practica la solidaridad porque ésta supone romper con los lazos de la familia tradicional para apoyar al extraño; sabe que no se es nunca solidario con los suyos sino solo en relación a los extraños. Claro que no todos los niveles de solidaridad son igualmente eficaces; cuanto más forastero el destinatario más revolucionario será el acto solidario. Profano-revolucionario es trabajar en contra del racismo, en contra de los controles de la sexualidad y del matrimonio, en contra de la educación sexista, por los derechos de las mujeres y los niños, por la salud cada vez más completa para todos, por una vida cada vez más larga y con tiempo más libre por un medio ambiente saludable. La democracia "occidental y cristiana" será útil a este fin en tanto no se convierta también en un proyecto de las castas en el poder. "Profanizar" es revolucionar las relaciones humanas, no someterlas a controles ni del capital, ni del partido, ni del estado porque todos estos centros de poder son creados y mantenidos por el gran trasfondo familiar arcaico en el que el sujeto una vez fue generado.

La familia es amor, protección, seguridad pero además es sumisión, entrega y resignación. Estos valores, positivos y negativos son indispensables a la sicología humana pero lo serán menos con el paso del tiempo. El ciudadano del futuro sentirá amor y odio, pero se irá desprendiendo de los rasgos más brutales de su naturaleza arcaica. Se irá desprendiendo poco a poco del odio al otro por ser diferente, de la violación sexual, del asesinato, de la tortura, de la explotación del trabajo ajeno. La receta está en el desarrollo de la conciencia social, directa e indirecta, simple y compleja, en la comunicación y en las cosas, en la organización y en la acción inmediata. El cambio, llega en parte desde los medios técnicos de una sociedad digitalizada. Pero esta avalancha de nuevos medios de intercambio es muchas veces desbordante y actúa reforzando los lazos arcaicos. Por ello el intercambio de la información debe ser aprovechada en beneficio de la sociedad civil. De alguna manera, esta sociedad existe ya de una manera evidente en torno a los primeros logros civiles que se reconocen como tales en la constitución de los hombres y mujeres de la modernidad contemporánea. La construcción de la nueva sociedad, es inevitable, pero los caminos que conducen a su realización son muchos, ¿cuál elegiremos? Al estar atado - muy a su pesar- a una raíz arcaica, el profano amará y odiará desde su perspectiva. Sin embargo, no tiene otra ética que la que le obliga al distanciamiento de esta raíz arcaica. El profano no es liberal, ni anarquista, no es comunista ni capitalista; es modernista. Vive para el cambio hacia un nivel más alto de civilidad.

\section{Bibliografía}

Alfano, C.M. (2009) Bootom-up de-liberarsi, dalla delega alla delibera, dal partito al partecipato. Tesis Licenciatura. Universidad Federico II di Napoli, Italia.

Ballón, E. (2003) Participación ciudadana en espacios locales: notas para un balance necesario. Lima, septiembre del 2003. Consultado en diciembre del 2009. 
http://www.cholonautas.edu.pe/modulo/upload/ballon.pdf

Breiger, R. (2010) Control social y redes sociales: un modelo a partir de Georg Simmel. Revista Política y Sociedad. Universidad Complutense de Madrid, consultada en enero del 2010. http://www.ucm.es/info/pecar/Articulos/Breiger2.pdf

Blanco, I. y Gomá, R. (2002) Gobiernos locales y redes participativas. España, Ariel social.

Arendt, H. (1970) “On Violence”. Harvest book, Harcourt, Inc. ISBN: 978-0-15-669500-8

Bernal, J. D. (1970). "Science and industry in the nineteenth century". Bloomington, Ind.: Indiana Univ. Press. ISBN: 0-253-20128-4

Cortés Vásquez, J. (2011) “Nuevos movimientos sociales y uso de las nuevas tecnologías. Estudio de casos.” Disertación doctoral no publicada. Universidad Complutense de Madrid.

Dalton, R. y. (1992). Los nuevos movimientos sociales. Valencia: Edicions Alfons El Magnánim.

Etkin, J. Schvaysten, L (1989). Identidad de las organizaciones. Buenos Aires, Paidós Flores Morador, F. (2013); “After Capitalism: Modernism (Cyborgism). A contribution to a critique of Historical Materialism”. Lund University. Tryck: Media, Lund University.

ISBN: 978-91-637-4329-0

González, R.L. Molina, J.L. (2003) . Redes para reparar lo social . REDES, Revista Hispana para el análisis de redes sociales, Vol. 4 \#1 junio/julio 2003. Consultado en enero del 2010. http://revistaredes.rediris.es

Huntington, S. P. (1991). "The third wave: democratization in the late twentieth century". ISBN: 0-8061-2346-X

1lich, I. (1981), “Shadow work”, Marion Boyars Publishers Ltd. Open Forum Series--- ISBN: 9780714527109

Ibarra, P. y Grau. E. (2000). "Anuario de Movimientos Sociales. Una mirada sobre la red”; Barcelona, Icaria Editorial y Getiko Funazioa.

I Ibarra, P. y Grau. E. (2002). Nuevos escenarios, nuevos retos en la red; Barcelona, Icaria Editorial.

Leiva, Andrés. (2006) El tema de la participación de la psicología comunitaria en las políticas del nuevo trato. Revista Razón y palabra No. 18.

Richta, R. (1969) "Civilization at the crossroads: social and human implications of the scientific and technological revolution”, 3, expanded ed., White Plains.

Laraña, E. y Gusfield, J. (2001). “Los nuevos movimientos sociales. De la ideología a la identidad”. Madrid: Centro de Investigaciones Sociológicas.

Machado, J.A. (2009). “Movimientos sociales y activismo en red”. Presentado en el II Congreso Online del Observatorio para la Cibersociedad. Barcelona, 2-14 noviembre de 2004, GT-46. Redes Digitales: potencialidades de acciones colectivas en el siglo XXI disponible en http://www.forumglobal.de/jm/art04-05/movimientos_sociales.htm 
Revista Latina de Comunicación Social \# 071 - Páginas 398 a 412 \begin{tabular}{l|l|l|l|} 
Investigación financiada & DOI: 10.4185/RLCS-2016-1101 & ISSN 1138-5820 & Año 2016
\end{tabular}

Molina, J.L.(2004) La ciencia de las redes. Apuntes de Ciencias y Tecnología. No. 11, junio de 2004. Consultada en febrero del 2010. http://www.aacte.eu/Apuntes/archivo-revista-apuntes-deciencia-y-tecnologia/Apuntes_11.pdf

Sánchez Arce, M. V. Soarín Pérez, Tomás. (2005) Las comunidades virtuales y los portales como escenarios de gestión documental y Difusión de información. Anales de documentación, número 004 Universidad de Murcia. Espinardo España.

Piñuel Raigada, J.L. y Lozano, Carlos. (2006). Ensayo general sobre la comunicación. España, Paidós, 2006.

\section{Cómo citar este artículo / Referencia normalizada}

F Flores Morador, J Cortés Vásquez (2016): "Los nuevos movimientos sociales, el uso de las TIC y su impacto social". Revista Latina de Comunicación Social, 71, pp. 398 a 412

http://www.revistalatinacs.org/071/paper/1101/21es.html

DOI: $\underline{10.4185 / R L C S-2016-1101}$

- En el interior de un texto:

... F Flores Morador, J Cortés Vásquez (2016: 398 a 412)...

$\mathrm{O}$

...F Flores Morador et al (2016: 398 a 412)...

Artículo recibido el 5 de enero de 2016. Aceptado el 18 de abril. Publicado el 27 de abril de 2016. 